José Luis Villacañas Berlanga. Catedrático de Historia de la Filosofía en la Universidad Complutense de Madrid. Director y Fundador de la Revista Res Publica y Director de la Revista Anales de Historia de la Filosofía. Director de la Biblioteca Saavedra Fajardo de Pensamiento Político Hispánico. Sus principales temas de investigación son la historia de la filosofía y de las ideas políticas. Entre sus trabajos recientes se encuentran: Teología politica imperial y comunidad de salvación cristiana, Editorial Trotta, Madrid, 2016; Populismo, La Huerta Grande, Madrid, 2015; Historia del poder político en España, RBA, Barcelona, 2015.

Contacto: jlvillac@filos.ucm.es 


\section{ALGUNAS TESIS SOBRE SOFT POWER Y SUBSUNCIÓN REAL}

José Luis Villacañas Berlanga

Universidad Complutense de Madrid

\section{SOME THESES ON SOFT POWER AND REAL SUBSUMPTION}

DOI: $1017450 / 160102$

Fecha de recepción 28 de septiembre de 2015; fecha de aceptación 14 de noviembre de 2015. El artículo es fruto de un proyecto de investigación desarrollado en el Departamento de Historia de la Filosofía de la Universidad Complutense de Madrid.

\section{Resumen}

El ensayo analiza la problemática marxiana de la subsunción real, confutando su centralidad como clave del capitalismo contemporáneo. Si el pronóstico marxista más perspicaz con respecto al soft power atañe a la subsunción real, al mismo tiempo esta no puede adquirir el perfil de dispositivo ontológico, tal y como se destaca de los análisis de los textos marxianos de Antonio Negri. Valiéndose de la ayuda metodológica e histórico-conceptual del pensamiento de Max Weber, el autor subraya que las tensiones actuales entre el capital financiero, el capital industrial y el capital humano no se pueden teorizar en términos absolutos, y que su funcionamiento no se basa en una lógica determinista, sino más bien en una lógica reflexiva, procesual y adecuativa. 


\section{Palabras clave}

Subsunción real, soft power, ontología, absolutismo conceptual, Max Weber

\section{Abstract}

The essay examines the Marxian issue of real subsumption confuting its centrality as the key of contemporary capitalism. Even if the most farsighted Marxist prognosis about soft power concerns real subsumption, the latter cannot be considered an ontologic device, as shown by the analysis of Marxian texts developed by Antonio Negri. Using the methodological and historical-conceptual contribution of Max Weber thought, the author shows that the current tensions between financial capital, industrial capital, and human capital cannot be theorized in absolute terms and that their operation is not based on a deterministic logic but rather on a reflexive, processual, adaptive logic.

\section{Key words}

Real subsumption, soft power, ontology, conceptual absolutism, Max Weber

\section{Ontología y absolutismo conceptual}

No hace falta invocar a Maquiavelo para apreciar la diferencia entre realidades efectuales y conceptos. La izquierda mundial lleva tiempo con análisis conceptuales a la defensiva, intentando imponer los viejos conceptos a las nuevas realidades. En este proceder hay un eco del argumento ontológico que cristalizó las esperanzas de omnipotencia conceptual de los teólogos medievales. Hay algo de conservador, de esclerosis de mirada, en este aferrarse a viejos conceptos para hacer encajar las nuevas realidades. Negri ha sido desde años el arquitecto principal de esta estrategia teórica, caracterizada por un virtuosismo hermenéutico sutil de los textos de Marx a los que acompaña de una fenomenología de la vida cotidiana convencional. Sus análisis suelen partir de conceptos teóricos marxistas clásicos y buscan proyectar analogías y metáforas entre estos conceptos y las nuevas realidades para mantenerlos operativos. En estas proyecciones metafóricas solo tiene un rival en Agamben. Así, por ejemplo, la nueva metrópolis es el equivalente a la fábrica; los habitantes de la casa se han apropiado del capital fijo, el capitalismo ha vuelto al viejo estadio doméstico al hacer de la casa la máquina, el 
intelecto general es la red y, por fin, el capitalismo de la edad global se puede pensar como el capitalismo de la subsunción real.

Lo que hay en la base de este planteamiento es una filosofía de la historia, no una ciencia de realidades en el sentido weberiano ni una reflexión sobre los límites de la conceptualización. Se trata de que, sea lo que sea el futuro, tiene que ser analizado en función de los conceptos del materialismo histórico que permitieron comprender el pasado. La potencialidad innovadora de la historia, que Weber consideró como un libro blanco sobrecargado de sobrevenidos, se reduce a la de una productividad metafórica que concede sus variaciones a ciertas definiciones inmutables y básicas. Podemos decir que, entre la estructura conceptual y las producciones metafóricas, no hay un esquematismo capaz de condicionar el uso de los conceptos, que de este modo se despliega con una libertad absoluta. Aquellos para los que la historia es indisponible y no vale esta estructura determinante de los conceptos, sino una más reflexiva; para los que la historia no se rige por una teoría fuerte como la de la Crítica de la razón pura, sino por una conceptualización débil y defectiva como la propuesta en la Crítica del juicio, quizá se hallen mejor preparados para identificar lo nuevo como singular, no como mera metáfora de lo legal y determinante. Quizá una de esas novedades sea el uso de soft power. En este texto esperamos proponer razones para afirmar la novedad de este concepto y su irreductibilidad a toda prognosis basada en la teoría marxista.

La prognosis marxista que guarda máxima significatividad respecto del soft power es ciertamente la de la subsunción real. Con este concepto tenemos el centro de la prognosis del marxismo, pues profetizaba una situación que Marx no podía observar, sino solo proyectar. Aquí, como siempre, según nos recordó R. Koselleck, las profecías sociales solo pueden ser aproximaciones, no previsiones de detalle ${ }^{1}$. En el siglo XIX nadie sabía a ciencia cierta qué aspecto concreto podía tener la subsunción real de la totalidad social bajo el dominio del capital. Así que no poder estar seguros de lo que Marx presentía es exactamente lo que conocemos hoy. En este sentido, un poco de kantismo en ciencias sociales no estaría mal. La subsunción real quería identificar el momento en que el capitalismo constituía una totalidad orgánica capaz de mediar la totalidad de las relaciones sociales. Hoy sabemos que el capitalismo es una realidad triunfante, pero seguimos teniendo problemas con saber lo que sea totalidad. En todo caso, no sabemos si el capitalismo es total en el mismo sentido en que Marx pensaba que iba a serlo. Para Antonio Negri, al parecer, es algo bastante concreto. Él considera que la subsunción real

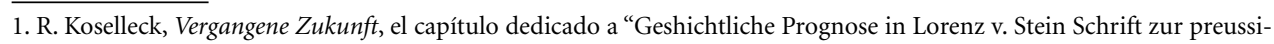
schen Verfassung”, Suhrkamp, Frankfurt, 1979, pp. 87-107. 
de la sociedad bajo el capital era no solo la conversión de la utopía de Marx en realidad. Era tanto una previsión científica realizada cuanto una "previsión política que ha sido obligada a realizarse" ${ }^{2}$.

El problema de la subsunción real atraviesa la obra entera de Negri. En su texto teórico más básico, Marx más allá de Marx, que es un seminario en la Ecole National Superieur impartido en 1978, ya la desarrollaba con amplitud. En realidad, cuando veinte años después volvió a editar el texto, reconoció que la predicción más notable de Marx era que el trabajo obrero industrial sería a partir de cierto momento secundario en la organización del capitalismo. Cuando el capital subsumiese enteramente a la sociedad, esa sugiere Negri que era la previsión de Marx, el trabajo productivo sería intelectual, cooperativo e inmaterial. En realidad, la predicción no era exactamente esta, como vamos a ver. El punto relevante es que, cuando sucediese la subsunción real, el proceso de la construcción del comunismo sería inaplazable. De nuevo, se repetía la vieja profecía de la socialdemocracia: cuando el capitalismo haya triunfado plenamente, comenzará su fracaso. Negri hacía una variación de esta profecía: cuando todo el trabajo sea intelectual, bastará liberar el trabajo intelectual, como base de toda producción, para poner en pie el proyecto comunista. Podemos decir que si la vieja socialdemocracia era la forma subjetiva adecuada al momento del trabajo industrial, propio de la subsunción formal, la multitud era la forma subjetiva adecuada a la subsunción real propia del trabajo intelectual. Una y otra estaban llamadas a cumplir una profecía que en el fondo era la misma, y que se aplicaba al pie de la letra a la evolución histórica del capitalismo.

De forma retrospectiva, en el prólogo que realizara para la reedición de esta obra, Negri invocó a un aliado que ya no podía objetarle nada. Se trataba de Gilles Deleuze y su trabajo La grandeur de Marx, un texto que el autor no pudo editar por su muerte repentina ${ }^{3}$. La clave de la transformación de Deleuze, según Negri, reside en "estudiar e identificar con precisión este hacerse real de la teoría marxiana como dispositivo ontológico". ${ }^{4}$ Nos permitimos subrayar el punto de la conversión de la teoría de Marx en dispositivo ontológico. No estamos muy interesados en averiguar qué encierra tal dispositivo. ${ }^{5}$ Consideramos que para Negri la dimensión ontológica del dispositivo es una

2. A. Negri, Marx más allá de Marx, Akal, Madrid, 2001, p. 8.

3. Ahora se puede ver de N. Thoburn, Deleuze, Marx and Politics, Routledge, London, 2003.

4. A. Negri, Marx más allá de Marx, p. 8.

5. Ibid., p. 9: "El comunismo, dice Deleuze, es un concepto que la fuerza de la multitud hace que se convierta en nombre común, un nombre que corresponde al modo de ser de la resistencia subjetiva, o sea, que deviniendo, dota de realidad a la utopía. El planteamiento epistemológico, cuando es crítico, siempre es utópico: su verdad, sin embargo, consiste en hacer que viva en el movimiento histórico de las multitudes, en el cerebro de los hombres, entre acontecimiento y acontecimiento, el devenir real del nombre común, en este caso, del comunismo". 
garantía de la praxis emancipadora, lo que en el fondo evoca el viejo reflejo de la socialdemocracia clásica de asegurar la revolución en la necesidad histórica. Así dice $\mathrm{Ne}$ gri que el comunismo se construye "Siguiendo siempre este dispositivo ontológico que transforma la crítica de lo existente en constitución común del 'nombre común"”. 6 Ese nombre común es comunismo. Así que la ontología del capital ofrece la clave que determina la emergencia de la dimensión subjetiva de resistencia, las multitudes. Pero por su base ontológica esta dimensión objetiva, depositada en el cerebro de los hombres, alcanza verdad y realidad. Esta traducción de las categorías de Marx en ontología constituye la aspiración secreta de buena parte del pensamiento del siglo XX en su búsqueda de un absolutismo conceptual teórico: unificar Marx con Heidegger para, de esta forma, ofrecer una reconciliación del marxismo clásico con el pensamiento posmoderno ${ }^{7}$. La multitud sería así "el esquema estructural de una nueva subjetividad" adecuada a la fase de subsunción real del capitalismo, a su dispositivo ontológico.

Por supuesto que en esta obra de 1978 ya se entendía que la diferencia entre subsunción formal y real era decisiva. ${ }^{8}$ Para Negri era la clave de la investigación marxiana y era saludada como de "extraordinaria actualidad". ${ }^{9}$ Este problema lo planteaba Marx en los Grundisse cuando analizaba el "grado en el que se ha constituido la comunidad real en la forma del capital". ${ }^{10}$ El texto de Marx, acerca del que Negri ya nos avisa que no pretende describir la subsunción real con rigor, ofrece un caso particular de eso que se llama un cambio cualitativo, ${ }^{11}$ o un "cambio en la naturaleza del capital". ${ }^{12}$ Por supuesto que Marx utiliza la metáfora orgánica, tan afín con la de la totalidad, como sabemos desde la Crítica del juicio de Kant. Ahora el organismo era el capital y todas las determinaciones sociales forman parte de su "composición orgánica". ${ }^{13}$ La forma en que esta producción orgánica se verificaba era la "sociedad-fábrica”. Marx había avisado de que con este progreso de la subsunción tendrían todavía que identificarse "las formas institucionales adecuadas", ${ }^{14}$ las variaciones que deben sufrir el Estado y el poder. Sobre esto, Marx no hace previsiones. En este vacío de previsiones resulta significativa la emergencia del

\footnotetext{
6. Ibid.

7. “El filón italiano, concentrándose sobre el concepto de 'general intellect' ha sentado las bases de una lectura de la posmodernidad absolutamente original”, ibid.

8. Ibid., p. 132.

9. Ibid., p. 133.

10. K. Marx, Grundrisse der Kritik der politischen Ökonomie. Negri cita por la edición de Dietz Verlag, Berlín, 1953. Seguimos con esta edición.

11. A. Negri, Marx más allá de Marx, p. 133.

12. Ibid., p. 132.

13. Ibid., p. 133.

14. K. Marx, Grundrisse der Kritik der politischen Ökonomie, p. 430.
} 
soft power. Sin embargo, el movimiento de Negri, más que rellenar con lo imprevisible histórico factual los vacíos de las previsiones teóricas, intenta condensar la predicción teórica para desde ahí imponer su esquema -determinar-a lo imprevisible histórico y a sus formas de poder.

\section{El sentido de la subsunción real}

Lo que el texto de Marx dice de verdad es algo bastante técnico e históricamente determinado: la subsunción real retirará toda función productiva a la renta social y logrará que la tierra entre en el mercado. ${ }^{15}$ Su intervención en la producción es sustituida por el capital en cuanto capital. Lo que venía a significar en concreto este hecho es que el tiempo de la acumulación originaria se había acabado. Esto significaba en realidad que todas las necesidades sociales eran atendidas bajo la forma del cambio. Así que Marx pone en relación la capitalización de la riqueza social y la satisfacción de todas las necesidades mediante el mercado. ${ }^{16}$ Marx insiste en este aspecto de atender todas las necesidades, incluso aquellas de especificidad común, mediante el intercambio, lo que implica que la renta de la tierra en especies haya desaparecido. Así que en cierto modo la subsunción real no parece tener que interpretarse, como a veces lo hace Negri, como un acontecimiento, un Ereignis que abre la puerta a la emancipación futura. Es, como diría el sobrio lenguaje weberiano, la condición específica por la cual todas las necesidades de las masas se resuelven mediante la producción a través del mercado. Pues, como añadiría Weber, esta solución de necesidades a través de la producción para el mercado es lo que en realidad produce capital. La subsunción real describe con sencillez el momento histórico en que todo bien económico alcanza su integración en la serie mercancía-dinero-mercancía.

Marx estaba muy interesado en los procesos de aceleración del intercambio, en la ganancia de espacio mediante la ganancia de tiempo, como condición de una circulación que alcanza a la totalidad de la sociedad. De tal manera que podemos decir que cuando W. Rathenau escribió su fenomenología del tiempo presente, en el famoso libro Kritik der Zeit, ya estaba en cierto modo verificando las previsiones marxistas. Sabemos que en sus escritos sobre el Estado nuevo y la nueva economía intentaba aclarar las formas institu-

15. Ibid., p. 438.

16. "Esto muestra en qué medida la riqueza social reproductiva está capitalizada y todas las necesidades son satisfechas en la forma de cambio". K. Marx, Grundrisse der Kritik der politischen Ökonomie, pp. 430-431. 
cionales del nuevo capitalismo. ${ }^{17}$ Negri no hace sino leer un texto de proyección científica marxista como si fuera un profeta que lee un texto bíblico: las promesas marxistas, todo lo que fue escrito, se cumplen precisamente ahora, ante nuestros ojos. La función de la ontología en el fondo esconde una economía del tiempo de la salvación y reside en asegurar esa proyección teórica sobre el presente. Pero, en el fondo, Negri no logra separarse de la necesidad de pensar la historia como la inevitabilidad del acontecimiento previsto en la teoría, que así atraviesa la economía de la epocalidad del tiempo. Desde este punto de vista, repite la obsesión del pensamiento moderno por determinar el tiempo histórico y la obsesión de la vieja socialdemocracia: liberar el capital de sus obstáculos, revelarlo en todos sus efectos es abrir por fin el camino a la "posibilidad de la subversión”. ${ }^{18}$

Sin duda, Marx hablaba de mercado mundial y de la universalidad del tráfico de mercancías y desde luego no hacía sino desplegar los pensamientos hegelianos sobre la mediación universal de la máquina. Hablaba de una perspectiva de filosofía de la historia como proceso en el que nada constituía un límite sagrado, y donde lo que se debía producir ante todo era el desarrollo completo de las fuerzas productivas como condición de producción. ${ }^{19}$ Era una revolución permanente del capital, comenta Negri. Esto no cambiaba la problemática de la alienación para Marx, ni tenía nada que ver con el auge del trabajo intelectual, inmaterial o cooperativo. Como sabía Weber, por el contrario, el proceso colocaba al individuo ante una riqueza ajena que le condenaba a trabajar en el seno de una expropiación general de los medios de producción. Pero en lugar de ver este proceso como un dinamismo económico autónomo, que deja la producción de capital a la lucha de precios, Negri mantiene que "únicamente la lucha de clases mueve al capital". ${ }^{20}$ Su evidencia teórica es el texto de Marx en el que dice que el capital no puede llegar a negar el tiempo de trabajo necesario como condición de su reproducción y de valor. Sin embargo, esto es lo que hace la subsunción real. Por tanto, el capital entra en su fase contradictoria. "Un desarrollo de las fuerzas productivas materiales [...] suprime en un cierto punto al capital mismo". ${ }^{21}$ Eso es lo que anunciaba Marx.

17. Cf. W. Rathenau, La triple revolución (Tres ensayos): El nuevo Estado, la nueva sociedad, Biblioteca Nueva, Madrid, 1919. Para una introducción a este autor olvidado, véase la versión castellana por Catalina Grossman y Alfredo Cahn, Walther Rathenau a través de sus obras, Instituto Americano de Investigaciones Sociales y Económicas, Buenos Aires, 1942. En italiano se puede consultar la edición de Roberto Racinaro, Lo stato nuovo e altri saggi, Liguori editore, Napoli, 1980. Todavía es útil la biografía que le dedicó el conde Harry Kessler, recientemente reeditada, Walter Rathenau: His Life and Work, Read Book, 2008. Más actual, la biografía de Shulamit Volkov, Walther Rathenau: The Life of Weimar's Fallen Statesman, Yale University Press, London, 2014.

18. A. Negri, Marx más allá de Marx, p. 134.

19. K. Marx, Grundrisse der Kritik der politischen Ökonomie, p. 440.

20. A. Negri, Marx más allá de Marx, p. 135.

21. K. Marx, Grundrisse der Kritik der politischen Ökonomie, pp. 441-442. 
En unas páginas más arriba se nos descubre la lógica de esta superación del capital y se nos muestra la dependencia de Hegel y su sistema universal de la máquina. Se trata de la diferencia entre trabajo vivo y trabajo de la máquina, que en Grundrisse (584-6) se presenta como un "poderoso organismo" (de nuevo la metáfora orgánica). Cuando esto sucede, el trabajo vivo es algo así como un "accesorio viviente de esta maquinaria". 22 Aquí aparece de nuevo la subsunción, pero ahora del trabajo vivo bajo el trabajo de la máquina. El "cerebro social", la acumulación de saber y habilidad humanizados, es subsumido por el capital fijo. Y por eso, el capital fijo es la forma adecuada del capital en general, mientras que el capital circulante es la forma variable frente al capital fijo. En ese sentido, el capital entraría en contradicción con el principio de la plusvalía. ${ }^{23} \mathrm{Se}$ reproduciría como capital, pero sin tiempo de trabajo necesario para la plusvalía. En el límite habría capital sin plusvalía. Cuando el proceso estuviera acabado, el capital trascendería en el momento en que todo fuese una variación de capital circulante y fijo. Pero sin trabajo vivo, este quedaría liberado del proceso capitalista y de este modo podría tornarse trabajo cooperativo, anticipando el comunismo. Esto sucedería, en la perspectiva de 1978, de una forma que Negri parece tomar de Lenin: "el capital circulante se despliega como capital productivo en la forma de la planificación y el control de la reproducción de la sociedad", dice. Y entonces tenemos la tesis de la subsunción real, que en el fondo no tenía otra previsión sino dar paso a la sociedad socialista sin tener que asumir la forma política y práctica de Gramsci ni la forma soviética de dominación: "La subsunción de la sociedad se ha hecho producción de la sociedad". ${ }^{24}$ Tenemos así en la subsunción real ese instante mágico en que el capitalismo se convierte en su contrario. El contenido de la subsunción real es, por tanto, la trasposición de todas las fuerzas del trabajo en fuerzas de capital, ya sea capital fijo o capital circulante. Por eso, dice Negri, "en este punto la apropiación capitalista de la sociedad es completa". ${ }^{25}$ Pero justo en ese momento, los seres humanos quedan liberados para el trabajo intelectual.

Negri reconoce que, en este curso de pensamiento basado en las proyecciones de Marx, hay "un cierto proceso mecánico de consecuencias", ${ }^{26}$ pero al mismo tiempo reconoce "un procedimiento lógico tan potente" y una "capacidad de anticipación tan

22. A. Negri, Marx más allá de Marx, p. 160.

23. Que está registrada en este punto: "El capital es la contradicción en movimiento, porque tiende a reducir el tiempo de trabajo a un mínimo, mientras que por otra parte pone al tiempo de trabajo como la única medida y fuerte de riqueza”. A. Negri, Marx más allá de Marx, p. 164. La consecuencia es que pone el trabajo superfluo como condición del trabajo necesario.

24. Ibid., p. 162.

25. Ibid.

26. Ibid. 
increíble", que lo hace irresistible. El argumento traía malas noticias para el marxismo, que ya Hegel había anticipado: la reducción de la dependencia del tiempo de trabajo. ${ }^{27}$ El hombre quedaba reducido a un "vigilante y regulador del proceso de producción". 28 En lugar de que la máquina sea el medio entre el hombre y la naturaleza, el hombre se desplaza al medio entre la máquina y la naturaleza. El argumento es hegeliano en sus entrañas. Así que el plustrabajo de la masa deja de ser condición de producción de riqueza. Como preveía Hegel, esto llevará a luchas sociales de permanente renovación. Negri sigue la consecuencia. Según sea la "potencia de la subsunción capitalista de la sociedad”, así emergerán dos "subjetividades plenas, contrapuestas, hostiles hasta el punto de su recíproca destrucción". ${ }^{29}$ Esto es lo que para Hegel hacía necesario el Estado: para atender la solidaridad nacional de los desplazados por la máquina que, como hemos visto, es el verdadero significado de la subsunción real. Entonces, el obrero queda fuera del proceso de subsunción y "la forma del valor es puro y simple poder de mando, pura y simple forma la política", ${ }^{30}$ dictadura del proletariado o dictadura del capitalista. Con su virtuosismo conceptual característico, Negri dice que este paso de la economía a la política, previsto por el propio Marx, se explica porque "la imposibilidad de la medida de la explotación modifica la figura de la explotación". ${ }^{31} \mathrm{Al}$ no tener en su base la plusvalía y el plustrabajo, toda la racionalidad capitalista implosiona y en su lugar aparece una "forma vacía de mando capitalista. Vacía y eficaz. Eficaz e irracional. Irracional y cruel". 32

Evocamos este texto para recordar que a partir de aquí Negri se pone poético. De la economía a la política y de la política a la poética. ${ }^{33}$ Bastaba poco para unir aquella vieja poética con la nueva de El trabajo de Dionisos, donde ahora se trataba de unir no a Marx y a Heidegger, sino a Marx y a Nietzsche a través de Spinoza. En realidad aludimos al mismo Grundrisse para decir que "el trabajo es el fuego vivo, formador, la transitoriedad de las cosas, su temporalidad, así como su modelación por el tiempo vivo" ${ }^{44}$ Dionisos pasó a ser el dios del trabajo vivo liberado. No se olvidaba de que el comentario de los

27. K. Marx, Grundrisse der Kritik der politischen Ökonomie, p. 592.

28. A. Negri, Marx más allá de Marx, p. 163.

29. Ibid., p. 164.

30. Ibid., p. 167.

31. Ibid.

32. Ibid., p. 168.

33. Se trata de la alabanza del individuo multilateral que tantos puentes iba a tender hacia el individuo posmoderno. Ibid., p. 170: "Deja de existir el beneficio porque deja de ser posible la traducción de la productividad del trabajo en capital. Deja de existir la racionalidad capitalista. La subjetividad no se libra simplemente a sí misma, libera por el contrario una totalidad de posibilidades. Identifica un horizonte. La productividad del trabajo se funda socialmente y se expande socialmente. Es simultáneamente un magma que todo envuelve y recompone, y un infinito despliegue de riachuelos de disfrute, de propuestas, de invenciones que recorren la tierra fecundada por el magma”.

34. A. Negri, M. Hardt, El trabajo de Dionisos, Akal, Madrid, 2003, p. 7. 
Grundrisse hacía irrelevante su aporte, pero sencillamente se transformaba la irrelevancia del trabajo para el capital en trabajo emancipado. Este es el arte del absolutismo conceptual. La novedad de la máquina electrónica, que no permite una expropiación radical, permitió el paso que garantizaba la metamorfosis de la irrelevancia del trabajo vivo en emancipación del trabajo intelectual como nuevo trabajo vivo cooperativo. En él estaban depositadas energías salvajes que las nuevas máquinas no inhibían, por mucho que las desearan domesticar.

Concluyamos. En la metáfora de la subsunción real hay algo así como un esquema vampírico. El capital poco a poco va absorbiendo la sangre de la sociedad civil hasta que ha logrado inocular en todo el cuerpo social su propio fluido: el dinero, de tal manera que a partir de ese momento la sociedad no tiene más vida propia, sino vida económica atravesada por las relaciones económicas de mercado. No es concebible de verdad este concepto sin un cierto organicismo, sin una relación biológica invasiva que determina que, a partir de un momento, bajo la misma apariencia del todo social, solo fluye una sangre económica. Esta perspectiva era bastante convergente con lo que pensaba el último Foucault: parece que hay biopolítica, regulación gubernativa de la vida, pero en realidad solo hay homo economicus. Parece que hay libertad, pero en realidad solo hay mercado. El concepto de subsunción real, en la medida en que encierra un dispositivo ontológico, tiene como finalidad renovar la diferencia entre apariencia y fenómeno real. Los hombres viven bajo la forma fenoménica de la sociedad, pero en realidad viven bajo la realidad de las relaciones económicas impuestas por la subsunción real. Pero cuando el proceso culmina, en realidad, los humanos viven ya una existencia póstuma, y no son necesarios para la renovación del capital. Entonces descubren que su trabajo intelectual ya puede ser comunista. De ser periféricos al capital se han convertido en centrales del comunismo, en multitud.

\section{El capitalismo moderno como sobrevenido}

Quizá convenga preguntarnos por los rendimientos teóricos y prácticos que puedan producir aproximaciones conceptuales que procedan de otras formas menos orgánicas y determinantes de observar la realidad social. Entre ellas, ninguna sigue siendo tan eficaz e instructiva como la de Max Weber. Él también tenía una visión del capitalismo como realidad, y es posible que sea interesante contrastarla, aunque solo sea como hipótesis alternativa a la de Negri. Dos elementos son los decisivos en la argumentación de Weber sobre el capitalismo racional moderno. Primero, que es un 
hecho histórico sobrevenido, imprevisto, no buscado, dado que las motivaciones que lo impulsaron estaban situadas completamente en otra parte, en la obsesión de obtener una certirtudo salutis accesible solo desde un entramado metafísico de intereses. Segundo, que justo por eso y por la estructura de irresponsabilidad y opacidad que lo produjo, el capitalismo se autonomizó respecto de sus forjadores y se convirtió en una máquina que funciona hasta cierto punto de manera automática. Aquí tenemos otra visión del capitalismo diferente de la subsunción real. Ciertamente, ha adquirido autonomía, pero esa autonomía es la de un cuerpo extraño, una máquina cuyas entrañas nadie penetra, porque es fruto de una producción inconsciente, a la que todos tienen que referirse y adorar, aceptar en su mediación, pero con el respeto, la desconfianza, el miedo propio de un dios que no está diseñado para el ser humano ni piensa en él, un dios catastrófico y tiránico. El virtuosismo de Negri, y de otros, es semejante al intento desenfrenado de los escolásticos tardíos de dominar ese dios con una redescripción de sus atributos conceptuales con el fin de prever y explicar sus efectos desde alguna forma de teodicea que transforme sus males en bienes y descubra su relación con el tiempo como una economía. Esta mirada sobre el capitalismo, más que racional, es puramente conceptual, pero no excluye, como sucede en todo virtuosismo gnóstico, el uso oportunista de algunos, que obtienen ventajas de la máquina justo por el manejo de determinados conceptos. Para eso, la máquina omnipotente debe ser pensada de tal modo que sobre ella se pueda ejercer control. Esto permite que los virtuosos dotados del absolutismo conceptual adecuado se eleven a sacerdotes, vicarios, profetas y augures de la máquina. Todos saben que la máquina piensa en sí misma y no en los seres humanos. En este sentido, el esfuerzo paranoide del absolutismo conceptual requiere que la totalidad esté condicionada por una maquina maquinorum, sin la cual se restringe de forma muy drástica cualquier capacidad de intervención. Este es el sentido de la subsunción real.

Para la mirada weberiana, por el contrario, el capitalismo es un hecho sobrevenido y nada puede cambiar ese estatuto. Puede que sea la realidad más poderosa, pero justo por su dimensión catastrófica y autónoma, no puede ser adorada por nadie realmente ni puede sobredeterminar la totalidad de la vida social y afectiva. Por tanto, los seres humanos siguen teniendo sus otros dioses y sus valores con los que lograr conformar sus daímones. Solo el capitalismo no se deja convertir en daímon. Algunos pueden sentir la fiebre de estar a su servicio y manejar algunos hilos al modo de ludópatas desaprensivos, pero a diferencia del eros, la belleza, la salvación psíquica, la producción de lo justo, el hallazgo de la verdad, el dios de la utilidad es inmanejable por el interés subjetivo en 
el largo plazo existencial. Todavía no podemos comprender como verosímil una personalidad humana que se deja subsumir completamente por el capital ni una sociedad que lo haga. El capitalismo goza de la paradoja de que solo se sirve automáticamente a sí mismo, pero no puede dominar el pecho de ningún hombre ni de ningún grupo en su totalidad, salvo que la noche polar haya congelado lo humano. En cierto modo, nos sigue pareciendo un imposible psíquico como motivo consciente autosuficiente y perenne de la acción humana.

Este esquema weberiano está diseñado para mostrar, de forma kantiana, las distancias entre el capitalismo y la subjetividad, por una parte, y las distancias entre capitalismo y la visión de totalidad del ser social por otra. El esquema weberiano implica que el capitalismo es inmanejable como totalidad evidente. No tiene una racionalidad inmanente plena y en esto es fiel a su origen sobrevenido y a sus entrañas, que se han formado a golpe de experiencias pasivas, no activas, de crisis y de renovaciones, de huidas hacia adelante, de vida pulsional. Esto significa finalmente que es inevitable en el terreno de los medios, pero no es absorbente en el de los fines. Sirve en cierto punto a la acción instrumental, pero no a la acción racional según sean los valores. La problemática de la subsunción real, cuando se la mira desde este esquema, choca con la falta de evidencia de que un mero medio pueda ser capaz de imponer una sobredeterminación total de la realidad. Comprendemos que estas categorías, que son insuperables en la estructura de finitud humana, sean miradas con ironía desde los restos de pensamiento idealista que laten en el fondo de los análisis marxista y neomarxista. Pero estas categorías, que proceden de la finitud, tienen la ventaja de que nos conectan de forma adecuada con el mundo de la vida y sus evidencias todavía sin congelar por completo. De forma adecuada, este planteamiento permite tener en cuenta la fenomenología de la vida social sin prejuicios conceptuales sistemáticos.

Subrayamos sistemáticos, porque los prejuicios conceptuales son inevitables. Sin embargo, hay una diferencia entre los prejuicios conceptuales que proceden de observaciones del mundo de la vida, obtenidos de la vida histórica y sus singularidades, frente a aquellos otros extraídos del sistema basado en un absolutismo conceptual-que ignora el carácter defectivo de los conceptos- y sus transformaciones metafóricas inconscientes de ser tales. Sin duda, el saber conceptual fragmentario y defectivo es menos imponente que el sistemático y es, desde luego, tentativo, parcial, histórico, reflexivo y finito. Sin embargo, nos hace estar más alerta para identificar lo desconocido y aunque nos despiste a veces, no produce esa extraña seguridad del saber sistemático que, si por acaso fuera 
inadecuado, nos descarría sin remisión. Porque la sensación de seguridad del sistema oculta las fallas en la descripción de lo real.

¿Qué ganancia obtenemos de esta apuesta por lo no orgánico, lo no total, lo no previsible? Creemos que una que nos permite distanciarnos de Marx y su organicismo del capital. Pues la relación entre el capital circulante, el capital fijo y el capital variable no forman un organismo, ni mucho menos. No constituyen un único capital que subsume a la totalidad de la realidad de la misma manera. Esto significa que las tensiones entre el capital financiero, el capital industrial y el capital humano no pueden teorizarse en términos absolutos. Tampoco puede teorizarse aquello que sustituye a la renta de la tierra, el capital material, el valor de las materias primas y que hace de sus propietarios algo parecido a Estados rentistas. Cada una de estas dimensiones del capital está determinada por la propia aspiración de cada una de estas formas del capital. Justo la imposibilidad de someter estas relaciones a una racionalidad general y sistémica es lo que ha determinado la emergencia de este especial soft power entendido como gobernanza. Sin el déficit radical del capitalismo como organismo, la gobernanza no tendría sentido. Pero lejos de la previsión marxista, no se trata de desnudo poder arbitrario. Su ideología es diferente: no depende de una lógica determinante, como la que está en el corazón mismo de la subsunción, sino reflexiva, tentativa, procesual, equilibradora, autocorregida, indiciaria, sintomática, reversible, reactiva, adaptativa, basada en la teoría de las catástrofes, en los argumentos de juegos, en lo que Laura Bazzigalupo ha llamado "incertidumbre ontológica", algo que creemos bastante diferente al llamado "dispositivo ontológico" e imposible de recoger en un absolutismo conceptual. El modelo del soft power es el de la crítica del juicio reflexionante, no el de la crítica del juicio determinante. Como vemos, es la forma adecuada a un capitalismo consciente de la imposibilidad de la propia planificación centralizada y eso habla solo de regulación. La pregunta que debemos hacernos es si ese soft power sobrevenido es la forma definitiva de gobernanza del capitalismo, y cuál puede ser su destino y el de la forma soberana de la política.

\section{No hay subsunción real, y por eso hay soft power}

Esta tesis no es intuitivamente evidente. En realidad es una especie de abducción. Sin embargo, cualquiera puede asomarse a sus premisas. El capitalismo no puede ser planificado y eso ha requerido una mediación en cierto modo reguladora y este es el 
alma de la gobernanza. Y esto en la medida en que, si tenemos en cuenta los avisos de Carl Schmitt, hechos en la cercanía de Weber, el capitalismo puede evitar la gramática de las decisiones en la medida en que las sustituya por estrategias de contención de consecuencias, de kathechon, que no hace inferencias acerca del funcionamiento de la caja negra de la máquina autónoma total. En este sentido, allí donde se cuenta con líneas rojas de contención suficientemente contrastadas respecto de la ignorancia de la caja negra, el capitalismo evita el gasto de las decisiones. Sin duda, esa caja negra es la del capitalismo global que nadie penetra, y la aspiración del soft power es producir efectos de equilibrio para producir la clave de toda evitación de decisiones, el tiempo, ahora invocado bajo el kathechon salvador del crecimiento. Si alguien puede argumentar que mantener los tipos de interés cercanos a cero contribuye a mantener el equilibrio capitalista mundial, a mantener la máquina en funcionamiento, entonces nadie entenderá su medida como una decisión en el sentido schmittiano del término, como algo que afecta a la lógica de la caja negra. Sirve solo para contener algunos efectos del molino diabólico autónomo, que sigue tan entregado como antes a su lógica ignota. En este mismo sentido, los actores de la gobernanza, verdaderos agentes imperiales, kathechónticos, podrán defender que son responsables ante el mundo, que promueve las relaciones no hostiles, que no toman medidas unilaterales, que se encarga de las estructuras interrelacionadas del mercado mundial. En fin, que no deciden.

Todas las medidas de lo que Nye define como soft power implican ya la ganancia kathechóntica, el largo plazo de la estabilidad económica, lo que a su vez implica que la gobernanza mundial es un sobrevenido indiciario del consenso de los poderes mundiales acerca del funcionamiento del equilibrio deseable del mundo. Nadie está inclinado a que la máquina ignota del capitalismo, que es hasta cierto punto extraña al poder de todos ellos, entre en crisis y se tenga que pasar a las decisiones. En este sentido, el capitalismo se ha convertido en la dimensión verdadera de la naturaleza y ha reocupado todos sus sentidos como productora de bienes en medio de una inhumanidad básica potencialmente catastrófica. ${ }^{35}$ No hemos desplegado este pensamiento, pero parece que es el futuro. No hablamos solo de la subsunción real de la vida social bajo las diversas formas del capital, sino de la vida general que tiene que ser vivida bajo una forma superior de naturaleza inmanejable, en la medida en que esa forma de capital no es orgánica. Esta subsunción peculiar, que no implica liberación del trabajo vivo ya emancipado,

35. Así Laura Bazzicalupo ha podido hablar de "capitalismo naturalizado", véase "L’Immaginario della crisi e lo spettro del cambiamento: falso movimiento", en L. Bazzicalupo, A. Tucci (eds.), Il grande crollo. É possibile un governo della crisi económica?, Mimesis, Milano, 2010, pp. 15-34. 
sino que ante todo implica conciencia de la improbabilidad de toda existencia, vida precaria, es la que se conoce como Antropoceno ${ }^{36}$. Así que la capacidad catastrófica de la naturaleza natural es ya parte de la naturaleza catastrófica del capitalismo. En cierto modo, la gobernanza es una regulación ecológica del capitalismo, como la ecología es una regulación capitalista de la Tierra.

Por supuesto que este equilibrio anhelado mantiene grados y márgenes. No todos los actores de la gobernanza tienen el mismo poder kathechóntico ni son partes equivalentes del dispositivo imperial. No es lo mismo el equilibrio que se permiten poderes como Brasil, que poderes como China. Por supuesto, esto depende de lo central que sea un país para la formación del equilibrio mundial. Además, esto implica que todavía hay instancias de decisión, solo que su presencia juega sobre todo para disuadir de tomar decisiones. Todos estos fenómenos, que conciernen a la fenomenología de la vida cotidiana, se derivan del aspecto inorgánico del capitalismo global, no del absolutismo conceptual de la subsunción real. Que todos los actores sean conscientes de que hay un amplio terreno de juego en el que no deben emerger las instancias de decisión, no significa que no existan. En realidad, las instancias de decisión están alerta y cuidan de que las demás instancias no tomen decisiones. Se trata de un desarme recíproco de actores que podrían estar listos a tomar las armas.

Por lo tanto, mientras la gobernanza del capital identifique la forma de detener las consecuencias de la caja negra de la máquina que hay que preservar en sus equilibrios, se genera el espacio de postergación de la decisión. Y a este ejercicio del poder que posterga las decisiones se le llama soft power. Así que la tesis acerca del soft power es que ofrece el dispositivo de kathéchon. Su verosimilitud es que la máquina capitalista seguirá bajo control homeostático de sus consecuencias. Los seductores bienes de cultura, de modo de vida, de equilibrio, de valores, de biopolítica, en los que se basa el soft power tienen como supuesto material que el ritmo de las innovaciones técnicas mantendrá activada la inclinación del ser humano al control de objetos. No debemos olvidar que la biopolítica actual promete, sobre todo, no política de la vida; sino política de los objetos ${ }^{37}$. Los argumentos sobre los que se basa el soft power que ejercen las autoridades chinas a favor de la multipolaridad, de la política de paz, de la serenidad

\footnotetext{
36. Se debe consultar la serie Critical Climate Change editada por Tom Cohen y Claire Colebrook, en Ann Arbor, University of Michigan y que aspira a estudiar las "epistemológicas mutaciones que corresponden a la temporalidad de la mutación terrestre".

37. Cf. J. C. Milner, La política de las cosas, Miguel Gómez Ediciones, Málaga, 2007, p. 23: "Porque la democracia moderna no entrega el gobierno de las cosas a los hombres, lo entrega a las cosas". Esto es ante todo una política de control en un sentido diferente del que anunció Deleuze, pero más preciso: "Se trata de evaluar a cada cual. Evaluar a los seres hablantes, en masa y con detalle, evaluarlos en cuerpo y en alma, a ese se llama control”, ibid., p. 15.
} 
en las relaciones internacionales, de la cooperación al desarrollo con amplias regiones de África y América tienen como condición de posibilidad que los beneficios de la formación del mercado mundial que conocemos desde el pacto Mao-Nixon se van a mantener en el largo plazo. Esa es su aspiración.

Pero quienes desde Weber y Polanyi avistan el capitalismo como un automatismo cuyas entrañas no se saben muy bien cómo funcionan, no pueden dejar de considerar que esta utopía de equilibrio en el fondo tiene bastantes probabilidades de que sea un artificio para decorar una huida hacia delante de la especie humana en su habitar sobre la Tierra. Este comentario tiende a plantearse la pregunta por la calidad de este dispositivo de kathéchon que es el soft power, uno que no es incompatible con la huida hacia adelante. Aquí, una vez más, los conceptos de nomadismo, errancia, carencia de espacio, todos los filosofemas que se toman de Deleuze, no son sino interregnos, afines a eso que en el fondo constituye al liberalismo básico del soft power; expresiones precisas de esa huida hacia adelante. Podemos sospechar que el soft power no es un poder sustantivo, sino la forma en que los agentes de la decisión actúan mediante delegados aplazando las decisiones. Podemos suponer igualmente que los poderes decisivos son competencias de reserva que entrarán en juego si la situación se sale de control. Pero si lo hace, y cuando lo haga, la máquina negra del capitalismo dejará de ser el artefacto autónomo que funciona a su aire, para dejar paso a la lógica bien humana de la dominación política soberana. Frente a ella, es lógico que esta actuación de gobernanza tenga como aspiración central posicionarse en relación con la máquina capitalista, cuya exterioridad en cierto modo permite que la gobernanza se presente como imparcialidad, objetualidad, dominio de un gestellt que necesita el poder que pueda no tanto manejarlo a voluntad (nadie desea repetir la omnipotencia de los poderes totalitarios que cayeron víctimas de la ilusión megalómana del voluntarismo), cuanto impedir que sus aspas diabólicas generen el peor daño en su propio territorio. Aquí, de nuevo, espacio, territorio y población siguen siendo las coordenadas de los aplazamientos mundiales. Por ellas tiene sentido el soft power, exactamente igual que el hard power.

El día en que el horizonte del actual equilibrio mundial se torne improbable, el día en que la máquina capitalista no pueda ser controlada en sus efectos; esto es, el día en que sus efectos se conviertan en diabólicos, entonces el soft power no podrá seguir ocultando la realidad de que en el fondo es un delegado del hard power. Por eso, justo porque no hay eso que se llama subsunción real, hay soft power, poder katechóntico, poder de consecuencias, no sustantivo, enraizado en la caja negra ignota del capitalismo. Pero justo porque no hay subsunción real, tampoco hay soft power como última instancia. 


\section{No hay soft power sin hard power}

Esta tesis, sin duda, es afín a la anterior y muestra con toda claridad que el capitalismo global no es el orden radical del nomos de la tierra. Esta última frase es una sencilla forma de decir que no hay subsunción real y que la esfera de la política sigue alentando al margen de la caja negra del capitalismo. El capitalismo global es la forma económica específica en que se mantiene un orden global nuevo, único, singular. En realidad, el capitalismo global es el orden económico en el que se refleja el triunfo de ciertos poderes mundiales. De nuevo, lo que en realidad está en la base de la derrota de la Unión Soviética es sencillamente la evidencia de que, a pesar de disponer de un armamento poderoso, la Unión Soviética no podía sobrevivir aislada del comercio mundial si China entraba en relaciones comerciales intensas con Estados Unidos y sus socios. La caída del muro de Berlín comenzó en la entrevista Nixon-Mao. Así que el orden mundial que siguió a la Guerra Fría, y que condujo a la victoria de los Estados Unidos de América sobre la URSS, fue la victoria del soft power de la gobernanza económica sobre las formas de la decisión política propia de los poderes imperiales de la Guerra Fría. Porque los Estados Unidos no pueden soñar que su relación con China sea imperial al viejo estilo, es inevitable que sea soft power. Esa arma de victoria, la gobernanza de un orden económico global, por tanto, fue la decisiva para instaurar el nuevo orden mundial, pero es un arma más, no la única que gobierna el nuevo orden mundial. En cierto modo fue una respuesta al camino bloqueado del hard power que había dejado las cosas en el empate catastrófico de la Guerra Fría.

Pero en todo caso, esa arma no habría funcionado sin la ayuda del hard power, pues lo que se ventilaba era una forma de hegemonía mundial. Lo que provocó la caída de la URSS con la celeridad que conocemos fue que se supo mantener la presión hard y soft. Hard sobre la URSS, con el programa de misiles antimisiles conocido como Guerra de las Galaxias impulsado por Reagan, y el soft sobre la China y la política de desarme arancelario y de libre comercio que implicaban a China en la futura gobernanza mundial. El escenario sorteó la esclerosis de la ONU, que como gremio de vencedores de la Segunda Guerra Mundial bloqueaba toda reforma del orden mundial. Ese escenario dividió a las elites chinas y permitió el ascenso de Den-Chio-Ping, con lo que marcó el rumbo de una revolución que aisló internacionalmente a la URSS. Esta experiencia es constitutiva de los análisis que llevaron a la definición del soft power por parte de Nye. Pero también es constitutiva de la diplomacia china y de la forma de ejercer su influencia internacional, mediante créditos en mejores condiciones que el FMI, política de equilibrio y de armonía 
internacional. En suma, la experiencia del triunfo americano de la Guerra Fría es determinante para entender el statu quo, que ya no es el resultante de la Segunda Guerra Mundial, razón por la cual la ONU ya no tiene relevancia alguna para solucionar los conflictos mundiales.

En todas sus proclamas, los teóricos del soft power afirman que el despliegue de este tipo de poder no significa que se descuide el hard power. Lo que significa realmente es que solo si se limita de forma considerable el uso del hard power, el orden mundial que ha sucedido al forjado tras la Segunda Guerra Mundial podrá ser un orden americano. Acerca de este hecho no basta con las proclamas de Negri acerca del nuevo poder de mando imperial. ${ }^{38}$ La preocupación fundamental de los teóricos del soft power es cómo los Estados Unidos pueden seguir siendo hegemónicos en el mundo. Hacerlo solo como hard power es muy caro. Cuando el soft power entra en juego no solo es barato sino beneficioso. La capacidad de seducir al mundo con sus Ipad, Iphones, industria cultural, industria del entretenimiento, formas musicales no hace sino abrir mercados, que se regulan y aseguran con las agencias de gobernanza. La clave de este soft power es que, además de concernir a los sentimientos, existencia y afectos, tiene efectos económicos importantes, abre mercados, y tiene como condición que se respeten las leyes de la propiedad intelectual. Por tanto, en cierto modo, el problema conceptual del soft power reside en que no logra identificar si es una forma de marketing de los productos característicos de la American Way of Life o si debe incluir el poder económico como herramienta diplomática. Pero en todo caso, implica una separación entre los poderes decisorios de la política y los poderes reguladores de la gobernanza, pues solo esta separación permite su eficacia kathechóntica de ganancia de tiempo. En suma, estamos ante una teoría imperial de nuevo cuño, que Negri no ha tenido en cuenta en su famoso análisis. ${ }^{39}$

Como dice Laura Bazzicalupo en el Editorial a la revista Soft power, este modo de pensar es estratégico y modal, y se muestra capaz de interconectar todos los aspectos de la vida. Su potencial carácter de capilaridad, informalidad, complejidad, responde bien a la carencia de organicidad del capitalismo actual y de nuevo falsea la tesis de la subsunción real. En su proliferación continua de diferencias puede aspirar a tejer un espejo de la productividad de la vida económica, evadiendo así la forma nítida y visible de la representación política. Mientras que esta trabajaba con una proyección de la complejidad de la vida económica sobre el punto de fuga de una trascendencia soberana, 
la gobernanza funciona enviando delegados fragmentarios de la vida económica con la aspiración de que su cruce permanente de información genere una imagen como en un mosaico de la vida económica, aunque nadie la vea entera. En todo caso, permitirá que cada pieza tenga suficiente información de las piezas laterales como para dotarse de un perfil y un límite, y así aprenda a conocerse a sí misma. Cada una de ellas, por tanto, asume la lógica de la pluralidad y de la diferencia, completamente ajena a la de la soberanía. Su régimen de verdad no está dictado por nadie, sino hallado en el propio proceso de articulación de las relaciones próximas, configurando grumos de ajuste. No hay un observador de la totalidad, pero todos observan los fragmentos del puzzle que definen su posición. Está la estructura de las relaciones horizontales que caracteriza el soft power. ${ }^{40}$ Su relación con las estructuras verticales del poder político se enfrenta al problema de conquistar el mínimo consentimiento con el que el nuevo republicanismo comprende la forma de dominación legítima. ${ }^{41}$

Esta relación define la lógica del presente como relación de tensión entre la esfera económica y la esfera política. Pues si bien la primera proyecta unas expectativas derivadas del principio de placer asentado en el trato permanente con objetos, la segunda sigue monopolizando las exigencias de seguridad existencial ante las catástrofes ya igualmente naturales del capitalismo y de la tierra. Si queremos ofrecer un soporte antropológico a esta ontología del presente, podemos decir, más allá de Foucault, que la gobernanza soft power realmente gobierna el principio de placer, generando tiempo, mientras que el Estado sigue regulando y ordenando de forma masiva la pulsión de muerte y el miedo existencial. En la medida en que estas pulsiones se mantengan en equilibrio, dando tiempo y conteniendo la llamada amenaza del terrorismo, soft y hard power podrán tejer su camino convergente. En la medida en que el Estado siga gobernando esta dimensión pulsional, sin embargo, implicará una dimensión espacial y un borde territorial (algo que el principio de placer más bien desconoce), y desde luego alcanzarán una dimensión pública, y en este sentido, en los asuntos en los que todavía interviene el Estado podrán venir connotados por otros aspectos existenciales no vinculados al principio de placer, como la vida, la familia, los antepasados, el sentido de la salvación, la cultura. De ahí la profunda asociación del principio de muerte con la problemática de la religión y su imparable dimensión pública. Desde este punto de vista, no hay subsunción real

40. Véase L. Bazzicalupo, "Editorial”, en Soft Power, 1, 2014, p. 14.

41. Este concepto de gobernanza fue teorizado como compatible con la forma republicana por Philip Petit, cuando defendió que el gobierno no necesita sino consentimiento para elevarse como ajeno a la dominación. Para él es una exposición de este problema, cf. mi nota sobre su libro. P. Petit, “Republicanismo y Dominación. Una crítica a Philip Pettit”, en Daímon, Revista de Filosofia, 27, Universidad de Murcia, sept-dic. 2002, pp. 73-89. 
porque no hay sometimiento de un principio psíquico a otro. La visión ontológica de Deleuze y la alegría impenitente de Negri, así como el principio del cuidado de sí de Foucault, no reconocen el principio de muerte, lo que concede a sus análisis una limitación importante porque desconocen la lógica profunda del Estado. Desde este punto de vista, son parasitarios de la situación que el soft power quiere regular, aunque tiendan a extremar sus poderes panópticos de control. Esta proyección es el rendimiento de su absolutismo conceptual, pero no identifica la realidad meramente parcial del soft power.

Toda fenomenología de la gobernanza debe llevarse a cabo en este contexto y prestarle así sus límites. Pues desde la teoría de la pluralidad de esferas de acción weberiana caben especializaciones que atienden dimensiones antropológicas. ${ }^{42}$ El gobierno económico neoliberal, que solo puede ejercer soft power, no puede atender todas las dimensiones del antiguo gobierno pastoral, que organizó un régimen de relaciones entre el principio de placer y de muerte. ${ }^{43}$ La representación tradicional política intenta reactivarse de forma continua despertando la pulsión de muerte, especializando al Estado en esas prestaciones existenciales, oportunamente intensificadas por el terrorismo global, por los elementos de las políticas de identidad bajo la presión de la emigración, por la atención mínima bajo condiciones precarias de crisis económica, que es la otra cara de la creación de las condiciones de un mercado que siga haciendo llegar objetos al dominio del placer de los seres humanos. Esta constelación es la que encaja de forma tan intensa neoliberalismo y populismo. Así que lo nacional no solo no se desmantela, como sugiere Maria Rosaria Ferrarese, ${ }^{44}$ por la gobernanza económica. Los efectos de la gobernanza económica también generan una reactivación de componentes selectivos de lo nacional, relacionados con la pulsión de muerte. Sin duda alguna, esto implicará una conexión entre democracia y pulsión de muerte que debe pasar inexorablemente por las formas populistas, que desplazará las formas de representación política hacia aspectos afectivos, sentimentales, compensatorios.

Así que a la hora de apreciar una fenomenología del presente tenemos que disponer de una mirada articulada que se muestre capaz de apreciar la diferente evolución de las distintas esferas de acción social y del aparato psíquico que las sostienen. Desde luego,

\footnotetext{
42. Cf. para este asunto mi trabajo, J. L. Villacañas Berlanga, “Esferas de acción y sistema psíquico. Entre Freud y Weber”, en T. Rocha Barco (ed.), Miscelánea Vienesa, Universidad de Extremadura, 1998, pp. 219-249.

43. Aquí disentimos de Maria Rosaria Ferrarese, que asume que los aspectos de la gobernanza incorporan "reglas que no están dadas a priori, sino que son el resultado de la adaptación y de la conducta adaptativa que toman en cuenta las necesidades de los gobernados, siguiente el modelo pastoral cristiano". Ibid., p. 50. La gobernanza no tiene aspectos comunitarios, sino contractuales y societarios. Por eso no puede hacerse equivaler al gobierno pastoral cristiano, que está mucho más allá de estos aspectos.

44. M. R. Ferrarese, “Governance: A Soft Revolution with Hard Political and Legal Effects”, en Soft Power, 1, 2014, p. 43.
} 
la gobernanza "es un paso ulterior en el camino de la secularización y de la pérdida del carácter místico y teológico de las instituciones públicas”, ${ }^{45}$ pero puede todavía venir compensada por una presencia a otros niveles de aspectos que no son tan unívocos a este respecto. En cierto modo, la gobernanza muestra la necesidad de desactivar la omnipotencia de la democracia como disfuncional para gestionar la complejidad del capitalismo, pero también deja abiertos los caminos para una ritualización de los aspectos democráticos conectados con los profundos problemas de identidad, subjetividad, afectividad y comunidad y pasionalidad.

\section{Nomos de la tierra}

Gobernanza imperial y Estado existencial subyacente ofrecen, entonces, el verdadero rostro de lo que el dogma marxista llama subsunción real, pero en su conjunto describe un horizonte lejano a las previsiones de un poder desnudo, brutal. Se trata solo de una especialización, de un nuevo régimen de división de poder que no diluye el núcleo del hard power por mucho que lo funcionalice en una nueva situación. Por eso el presente no queda bien descrito ni desde una fenomenología que absolutiza la gobernanza, ni desde la ontología del marxismo, que hace de la gobernanza un mero espejismo ideológico de una realidad profunda que la teoría controla y domina conceptualmente. Desde luego, la fenomenología de la gobernanza está preparada para mostrar su facticidad, sus aspectos neocorporativos y neofeudales, sus cambios en el sentido de la ley y la orden administrativa, aspectos que son diferentes a los de una excesiva sistematización ontológica. Por supuesto, en esa fenomenología debe entrar el contexto temporal de la economía, que aspira a una ganancia de tiempo al servicio del principio de placer, completamente ajeno a la temporalidad de la pulsión de muerte. No se debe olvidar que, a pesar de todo, esa apariencia de caos es funcional para mantener en perspectiva un ámbito de calculabilidad que todo orden capitalista necesita y promete. ${ }^{46}$

\footnotetext{
45. Ibid., p. 45.

46. Véase ibid., p. 56. Aquí la autora cree que la gobernanza se opone al principio weberiano. Creemos, por el contrario, que no es así. Estamos de acuerdo con la descripción que le permite a la gobernanza ofrecer un "espectro de elecciones extremadamente diferenciadas, reglas y prácticas legales, de acuerdo con diferentes criterios y racionalidades, con las que el capitalismo de hoy día se reserva el derecho de tomar sus propias decisiones dependiendo de las circunstancias. Gobernanza, en esta gran indeterminación, representa un vasto reservorio para esta diferenciación jurídica extrema”. Pero en nuestra opinión esto es justo lo que ofrece a la gobernanza su calculabilidad. En esta medida, sigue obedeciendo a la lógica jurídica que necesita el capitalismo.
} 
Pero ahora abordaremos el último problema, que no es otro que los efectos hard que en el medio plazo pueden tener las diferentes formas soft de la gobernanza. Este aspecto solo se podrá estudiar cuando abordemos el tema del futuro nomos de la tierra y cuando reflexionemos sobre el papel de la hegemonía mundial que se debe suponer en este contexto. Aquí debemos recordar algo. Cuando Estados Unidos se embarcó en las nuevas relaciones con China, ya era consciente de que su forma de mantener la hegemonía mundial no podía ser la propia de una potencia imperial del viejo estilo, pues sabían que China, a diferencia de Japón y de Europa, jamás entraría en una relación de socio subsidiario imperial con Estados Unidos. En este sentido, la forma de la gobernanza económica juega de manera diferente cuando se trata de países como China, que son los únicos que pueden sobredeterminar la gobernanza económica a su favor, respecto de otros que tienen una lógica más subsidiaria, como por ejemplo Europa.

En este sentido, la categoría de soft power ha recibido una buena recepción en los servicios diplomáticos chinos, porque parece obvio que China no tiene veleidades de intervención militar más allá de sus fronteras y ha hecho de esta decisión una característica específica, frente a la vieja URSS y frente a Estados Unidos. Así, China ha caracterizado el soft power en relación con su concepción tradicional de la vida, intentando presentarse como un socio mundial no oportunista, que no juega con el palo y la zanahoria (que es la intuición presente en la base de la diferencia hard y soft power). ${ }^{47}$ China sería, por vocación y por cultura, un país de no intervención militar, de aislamiento militar, pero no cabe duda de que puede usar la gobernanza económica al margen de las agencias mundiales. Puede tratar a sus ciudadanos de forma autoritaria, pero es respetuosa con los huéspedes y los extranjeros, no tiene ideales expansionistas militares, y solo tiene una reclamación como finalidad de su soft power: crear un mundo multipolar. Eso es irrenunciable para su diplomacia. Para ello usará sus inmensas reservas de dólares, su capacidad de compra, su voluntad de equilibrio, su política de vecindad y armonía. Aquí, sin embargo, comenzamos a describir la verdadera situación. Pues por mucho que se trate ya de un único capitalismo mundial, parece que China aspira a que este tenga una traducción política de naturaleza multipolar, algo que ofrece el otro lado del aspecto ya señalado, del retraso de las decisiones soberanas. Esto implica que, bajo el fondo

47. La literatura sobre este asunto es muy abundante ya. Cf. J. Kurlantzick, Charm Offensive: How China's Soft Power is Transforming the World, Yale University Press, London, 2007. Cf. H. L.,Yiyi Lu, China's Soft Power and International Relations, Routledge, London, 2012. Mingjiang Li, Soft Power: China's Emerging Strategy in International Politics, Lexington Book, Plymouth, 2011. C. McGiffert, Chinese Soft Power and Its Implications for the United States: Competition and Cooperation, Center for Strategic and International Studies, 2009, Washington. Y el capítulo 5 de C. Hayden, "The Rhetoric of Soft Power: Public Diplomacy in Global Contexts", Lexington Book, Plymouth, 2012. 
unitario de la gobernanza, sigue existiendo el espacio y la Tierra y los centros soberanos de decisión por ahora inhibidos en su máxima expresión.

A pesar de la superficie homogénea de una gobernanza mundial, pendiente de equilibrar las consecuencias de la máquina capitalista en la que todos tienen intereses de ganancia de tiempo, los actores se mueven en otro escenario en el que las aspiraciones son otras, escenarios que siguen vinculados a las coordenadas de pueblo y territorio. Mientras que los Estados Unidos se mueven por una política de manos libres, en el que el soft power juega con estrategia como un ahorro de hard power, China y otros países usan el soft power con estrategia como un rechazo del hard power, desde luego, pero con la aspiración de configurar un mundo multipolar en el que los Estados Unidos no tengan las manos libres. En esta carrera ha entrado recientemente la India, con su proyección mundial como la patria de la serenidad, del yoga, del pacifismo, algo que el Brasil anterior a la crisis había intentado igualmente hacer con las danzas propias y el alegre estilo latino de trabajar bailando. Por tanto, como estamos viendo, al estilo de vida americano le están surgiendo otros estilos de vida, otras concepciones del mundo que muestran que, sin oportunismo, desde el fondo de la vida histórica, emerge un tipo de soft power que pretende, en último extremo, atar y condicionar el hard power. Ninguno de ellos pone en tela de juicio que el terreno de juego sobre el que se levanta la acción es el capitalismo mundial. Pero todos ellos juegan con la premisa weberiana: el capitalismo es una planta que puede crecer en cualquier sitio, y cada terreno acabará por darle su coloratura específica y por dotar a la misma planta con variedades autóctonas. En el espacio mundial, cada una de estas coloraturas se ofrece como ofertas de persuasión.

Solo el mero hecho de que surjan esos desafíos de soft powers diferentes, todos dotados de la misma aspiración de generar un mundo policéntrico, ya testimonia que hay una estrategia de prevención respecto de escenarios de toma de decisiones, pero sobre todo porque se teme dejar las manos libres a un poder hegemónico que no necesita ser decisorio, sino de mera inercia, para mantener su posición. Debemos decirlo pronto: tras estos actores de soft powers hay una aspiración a que cristalice un nuevo nomos de la tierra, que ya ha neutralizado como argumento el capitalismo (que se convierte en la base material de todos ellos), y se concentra sobre la dinamización de los aspectos civilizatorios de las grandes religiones y culturas mundiales y sus despliegues seculares. En realidad, el soft power es la concreción del diagnóstico weberiano de que las grandes religiones mundiales serán las que coloreen los poderes capitalistas del futuro. No debemos olvidar, en este sentido, la ofensiva del papado católico, como agente de visibilidad de los cristianos en el mundo. Frente a estas religiones y culturas claramente 
evolucionadas hacia el soft power, todas ellas potencias biopolíticas en cierta tensión con el capitalismo, se alzan las tres religiones que no han logrado separarse de su profunda inclinación al hard power, por su capacidad de vincularse de forma expresa con elementos de la pulsión de muerte: la judía, la ortodoxa y la musulmana, con su sentido del espacio, del suelo sagrado y entregado por Dios, de la sangre, de las tumbas de los antepasados. Como tales, marcan desde luego los límites de la eficacia de los softs powers del mundo, ya sea en Cachemira, ya sea en Jerusalén, ya sea en Ucrania, ya sea en Bagdad. Aquí, parece que las viejas civilizaciones cumplen con su destino histórico sin que la irreversibilidad de un proceso secularizador les amenace por completo. De este modo, tenemos que el soft power muestra su aspecto selectivo y limitado, incluso a veces oportunista, y desde luego vinculado con la diferencia espacial dentro/fuera. Pues el régimen de la armonía chino no duda en aplicarse hard frente a los guerrilleros islámicos de su territorio o contra los Lamas de Laos, ni el gran Yogui de Delhi deja de aplicarse hard contra las minorías musulmanas de la frontera de Cachemira.

¿Son, por tanto, el hard y el soft power un índice de intereses secundarios y de intereses vitales? No del todo. En la medida en que están implicados principio de placer y principio de muerte, desde luego que sí. Bien puede ser que allí donde rige la lógica económica quepan los poderes blandos. Donde el poder opera determinado por los medios capitalistas, sin duda alguna los medios softs pueden contar con un chance superior, pues esos mismos medios podrán ser tenidos en cuenta por todos los actores. Pero todas las gradaciones son posibles aquí. Y esto nos lleva a una tesis ulterior. Y es esta: no hay subsunción real, sino lucha por mantener un régimen de división de poderes bajo el campo de posibilidades que abre el capitalismo mundial. La inhibición de la decisión tiene que ver con la específica situación temporal de que, mientras tanto, ni se elimina la realidad de la hegemonía mundial de Estados Unidos, ni se ha perdido la esperanza de un universo político policéntrico. Ese tiempo es el de la gobernanza. En todo caso, pace Negri, podemos caracterizar este tiempo de las relaciones internacionales como dotado de una hegemonía imperial bajo una forma inorgánica de gobernanza destinada a erosionarla. Y sin embargo, tampoco podemos decir que la forma hegemónica esté completamente al margen de elementos imperiales hard power. Esto es importante y solo se verá en todas sus consecuencias cuando nuestros conceptos sean más operativos y menos sistemáticos.

Cuando observamos el presente no con el andamiaje asegurador de la teoría, sino desde el anclaje en el mundo de la vida histórico, apreciamos que la forma capitalista de la esfera económica, aunque se desenvuelve con el anonimato que caracteriza a su fun- 
cionamiento mecánico, no por eso presenta, desde el punto de vista de la esfera política, actores simétricos. Aquí, como en los demás tiempos históricos que gestionaron modos de producción, los actores subjetivos gozan de diferentes posiciones y privilegios. La penetración del capital en la vida cotidiana no se hace desde la forma abstracta de capital, sino que se realiza desde la forma concreta del dinero y la todavía más concreta de consumo de objetos con profundos rendimientos para el principio de placer. Pero el dinero no es una abstracción absoluta, sino una forma concreta de simbolizar un poder de disponer de objetos. El dinero no es ni hard ni soft, sino justo la capacidad de tener la máxima opción de elección entre el uno y el otro. Lo que llamamos subsunción real, desde el punto de vista del capital concreto, es la sobredeterminación por el dólar de los intercambios globales. Llamamos a este poder de disponer de la moneda mundial de cambio, que otorga las mejores condiciones para elegir entre soft y hard power, el otro elemento imperial del poder hegemónico, que hay que añadir a la superioridad militar incuestionable. Se trata del poder que se beneficia al máximo de disponer del numerario mundial o del capital circulante. Eso fue lo característico del poder imperial romano, como lo fue del poder imperial del Sacro Imperio o del Imperio español. Podemos llamar elemento imperial del poder hegemónico a aquel que puede aumentar el circulante sin que sea necesario producir inflación ni devaluación. Por más dólares que imprima la Reserva Federal, el valor del dólar no baja.

Nuestro escenario se cierra ahora. Cuando Negri definió el poder imperial en su célebre libro, en cooperación con Michel Hardt, se entregó a todo tipo de metáforas para evadir el único significado que en realidad se descubre cuando miramos el presente desde categorías inductivas de la conciencia histórica. Como sabemos, el poder sobre la moneda es todavía propio de las decisiones soberanas. Este poder nos permite decir que Estados Unidos goza de una hegemonía con elemento imperial. Sabemos que la capacidad de alterar el valor de la moneda es algo que afecta a los caminos de la subsunción real, pero no pertenece a la subsunción real. Por lo demás, bajar o subir tipos de interés es algo que afecta a la totalidad del sistema capitalista mundial. ¿Es parte del hard o del soft power? No está claro. En todo caso, es el elemento que determina la subsunción real y a la vez decide la condición hegemónica. Que China tenga su propia política monetaria implica que no ceja en su aspiración a generar un mundo plural. Los márgenes en que puede hacerse esto aquí ni siquiera están en la mano de los actores. Por mucho que la reserva federal quiera retirar los estímulos monetarios por razones internas, resulta claro que no lo puede hacer sin revaluar el dólar, algo que hunde las divisas latinoamericanas y sus equilibrios comerciales. China ha tenido que reaccionar con devaluaciones 
masivas, cuando Estados Unidos le pedía con insistencia que revaluara su divisa. Cuando se llega a estos escenarios ya se habla de guerra de divisas. De tal modo que cualquier uso de los poderes soberanos, cuando encierra elementos hegemónicos imperiales y sus consecuencias, ya no puede escapar al destino de ser una forma de guerra. La gobernanza no puede condicionar estas decisiones, sino jugar con ellas.

Con esto vemos que el orden mundial se basa en un equilibrio de constantes de la máquina capitalista, cierto, pero lejos de ser una subsunción real de toda la sociedad al capital, es más bien la configuración de un escenario capitalista en el que los actores no tienen la misma capacidad de participación a la hora de imponer el equilibrio. Alguien tiene no solo la capacidad de equilibrar, sino también la de desequilibrar completamente el sistema a su favor, porque tiene en sus manos la divisa en la que se produce esa economía global. Ese alguien no solo usa la moneda. Con ello tiene un elemento de gobernanza del viejo estilo soberano, que puede por sí solo desarticular y desestabilizar a su favor todos los acuerdos de gobernanza conseguidos sobre equilibrios y negociaciones. Esto nos pone en la pista de lo decisivo: el soft power de la gobernanza puede tener efectos hard porque puede apoyar hegemonía o policentrismo de poderes. Pero dado que la hegemonía tiene un elemento imperial tan poderoso, es fácil que lo que determine en última instancia la economía capitalista no sea una dimensión del capitalismo, sino de la política. Las negociaciones del TTIP ${ }^{48}$ lo dejan perfectamente claro. Las evidencias finales sobre las que emerge el pensamiento de Carl Schmitt no se pueden ocultar.

Este argumento marca el escenario de medio plazo del soft power. Por una parte mantiene el equilibrio de la fábrica mundial, pero por otra mantiene el desequilibrio de la moneda mundial de intercambios, un elemento imperial. Este es el significado de la hegemonía. Puede tolerarse la aspiración de pluricentrismo y el soft power chino, pero bajo un elemento hegemónico imperial. Con ello, se trata de un nomos de la tierra extraño y sobrevenido. Por una parte, se acepta el pluriversum. Pero se trata de uno desequilibrado en el que una potencia es hegemónica y quiere mantener la hegemonía. Y a eso sirve el soft power: a su mantenimiento y a su erosión. Para su mantenimiento se usan los sistemas de propiedad, de legislación, de normatividad y el sentido de la justicia con los que los Estados Unidos cierran tratados de comercio mundial que son específicamente políticos y que excluyen a China. Los tratados del Atlántico y del Pacífico están negociados bajo condiciones específicamente políticas,

48. Tratado Transatlántico de Comercio o Inversiones (por sus siglas en inglés Transatlantic Trade and Investment Partnership). 
jurídicas y técnicas, y de ahí su secreto. Por fuera de ellos, el comercio mundial sigue su camino también sobredeterminado por otras políticas soft power tendentes a generar pluricentrismo. Por tanto, en su conjunto, el capitalismo es anónimo y mecánico, pero la forma concreta en que se realiza históricamente es imperial y tiene en su base poderes imperiales, los cuales usan toda la gama de opciones a su mano, desde la hard pura a la soft pura, pasando por los poderes de la moneda a los poderes del espionaje. Y el problema que nos plantea no la teoría, sino el arte de vivir propio de esta experiencia histórica, es si estamos en condiciones de prever la manera en que el poder imperial del presente defenderá su posición de manos libres, frente a lo que pueden ser las exigencias de multilateralismo que emergen desde los más diversos escenarios. Pues lo que sabe todo poder imperial históricamente posicionado es que siempre hay más de un candidato al imperio. La historia nos dice que estos no son candidatos porque tengan los poderes suficientes, sino porque tienen historias específicas. La mayoría de las veces no pueden ganar, pero casi siempre pueden hacer perder. La conclusión que extraemos es si no sería más razonable comenzar a construir un nomos de la tierra consciente de la inviabilidad de un poder imperial hegemónico en el largo plazo. La teoría de la subsunción real oculta esta conclusión bajo un montón de teoría. 